\title{
Patterns of care: burr-hole cover application for chronic subdural hematoma trepanation
}

\author{
Julia Velz, MD, 1,2 Flavio Vasella, MD,, ${ }^{1,2}$ Kevin Akeret, MD, ${ }^{1,2}$ Sandra F. Dias, MD, ${ }^{1,2}$ \\ Elisabeth Jehli, MSc, ${ }^{1,2}$ Oliver Bozinov, MD,,2 Luca Regli, MD,,2 Menno R. Germans, MD, PhD, 1,2 \\ and Martin N. Stienen, MD, FEBNS, ${ }^{1,2}$ on behalf of the CORRECT SCAR study group
}

'Department of Neurosurgery, University Hospital Zurich; and ${ }^{2}$ Clinical Neuroscience Center, University of Zurich, Switzerland

\begin{abstract}
OBJECTIVE Skin depressions may appear as undesired effects after burr-hole trepanation for the evacuation of chronic subdural hematomas (CSDH). Placement of burr-hole covers to reconstruct skull defects can prevent skin depressions, with the potential to improve the aesthetic result and patient satisfaction. The perception of the relevance of this practice, however, appears to vary substantially among neurosurgeons. The authors aimed to identify current practice variations with regard to the application of burr-hole covers after trepanation for $\mathrm{CSDH}$.
\end{abstract}

METHODS An electronic survey containing 12 questions was sent to resident and faculty neurosurgeons practicing in different parts of the world, as identified by an Internet search. All responses completed between September 2018 and December 2018 were considered. Descriptive statistics and logistic regression were used to analyze the data.

RESULTS A total of 604 responses were obtained, of which 576 (95.4\%) provided complete data. The respondents' mean age was 42.4 years (SD 10.5), and $86.5 \%$ were male. The sample consisted of residents, fellows, junior/senior consultants, and department chairs from 79 countries (77.4\% Europe, 11.8\% Asia, 5.4\% America, 3.5\% Africa, and 1.9\% Australasia). Skin depressions were considered a relevant issue by $31.6 \%$, and $76.0 \%$ indicated that patients complain about skin depressions more or less frequently. Burr-hole covers are placed by $28.1 \%$ in the context of cSDH evacuation more or less frequently. The most frequent reasons for not placing a burr-hole cover were the lack of proven benefit $(34.8 \%)$, followed by additional costs $(21.9 \%)$, technical difficulty $(19.9 \%)$, and fear of increased complications $(4.9 \%)$. Most respondents $(77.5 \%)$ stated that they would consider placing burr-hole covers in the future if there was evidence for superiority of the practice. The use of burr-hole covers varied substantially across countries, but a country's gross domestic product per capita was not associated with their placement.

CONCLUSIONS Only a minority of neurosurgeons place burr-hole covers after trepanation for CSDH on a regular basis, even though the majority of participants reported complaints from patients regarding postoperative skin depressions. There are significant differences in the patterns of care among countries. Class I evidence with regard to patient satisfaction and safety of burr-hole cover placement is likely to have an impact on future CSDH management.

https://thejns.org/doi/abs/10.3171/2019.8.FOCUS19245

KEYWORDS chronic subdural hematoma; burr-hole cover; multinational survey; aesthetic outcome; patient satisfaction; skin depression

$\mathrm{C}$ HRONIC subdural hematoma (cSDH) is a common disorder, mainly affecting elderly people, with an incidence of 58 per 100,000 per year in those aged 70 years and older. ${ }^{6}$ There has been a steady increase in incidence as a result of increased life expectancy in developing countries, the widespread use of long-term anticoagu- lation/thrombocyte aggregation inhibitors (e.g., aspirin, warfarin, heparin), as well as an increase in therapeutic interventions such as ventricular shunting. $3,5,8$ Whereas smaller cSDH in asymptomatic patients or those with only a few symptoms may be managed with observation, treatment should be considered in patients with space-occu-

ABBREVIATIONS $\mathrm{Cl}$ = confidence interval; $\mathrm{CSDH}=$ chronic subdural hematoma; EANS = European Association of Neurosurgical Societies; GDP = gross domestic product; OR = odds ratio; RCT = randomized controlled trial; SSI = surgical-site infection.

SUBMITTED March 12, 2019. ACCEPTED August 14, 2019.

INCLUDE WHEN CITING DOI: 10.3171/2019.8.FOCUS19245. 


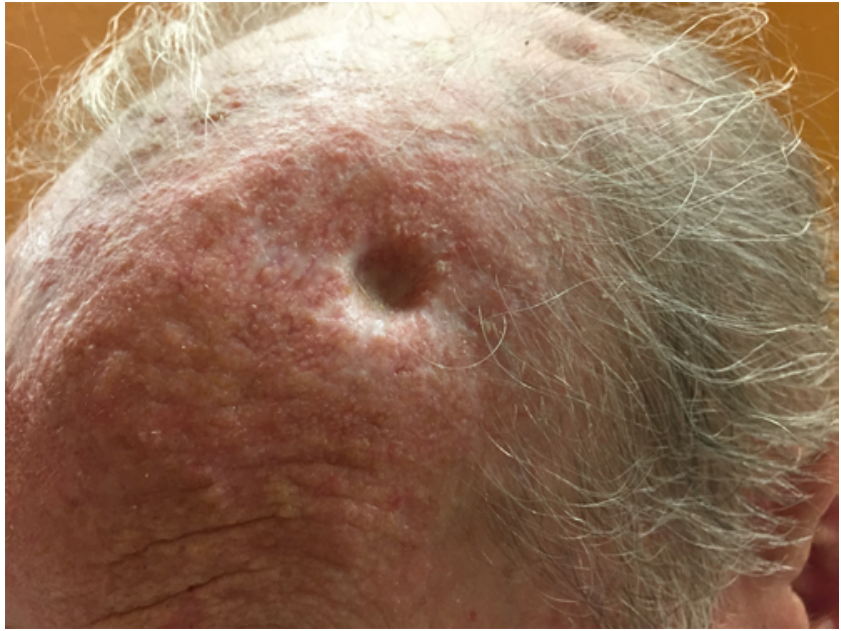

FIG. 1. Representative case. At the age of 88 years, this male patient underwent left-sided frontal and parietal burr-hole trepanation. He had a favorable response, with complete resolution of preoperative headache and right-sided hemiparesis. The photograph was taken with his permission about 2 years after the operation. The patient continues to lead an active life, and-upon inquiry-he and his wife indicate feeling troubled by the well-visible skin depressions.

pying hematomas and significant or progressive clinical signs and symptoms. ${ }^{1}$

With nonoperative treatment forms currently under evaluation, surgery remains the only existing treatment option proven to be effective today., ${ }^{1,5,9,14}$ While neurosurgeons converge on the general concepts of trepanation, followed by dural opening and evacuation of the hematoma, the patterns of care vary significantly among individual surgeons, departments and countries with regards to technical nuances: 1 versus 2 burr holes, twist-drill craniotomy or mini-craniotomy with endoscopy-assisted hematoma clearance, drain versus no drain, among others. ${ }^{1,2,4,7,9,10,12,13}$ A recent survey pointed out, however, that for nonacute hematomas, conventional burr-hole trepanation remains the most commonly performed procedure in most neurosurgical departments.

Despite their generally favorable risk profile and outcomes, burr-hole trepanations may lead to delayed scalp depressions and an unsatisfactory aesthetic outcome. Patients may feel troubled by stigmatization due to the visible skin depression, which typically develops over time with progressive hematoma resorption (Fig. 1).,12 Accumulating retrospective evidence indicates that the placement of burr-hole covers may prevent scalp depressions and may increase patient satisfaction with the aesthetic result of the surgery. ${ }^{4,12}$ However, placement of burr-hole covers is currently not the standard of care in clinical practice and the literature on this issue remains scarce. ${ }^{1,4}$ We have received several comments regarding a recently published article on this topic, ${ }^{12}$ and it appeared that opinions and patterns of care vary substantially among neurosurgeons with regard to burr-hole cover placement. Therefore, the objective of this study was to assess the practice variations among neurosurgeons in terms of burr-hole cover placement after burr-hole trepanation for patients with $\mathrm{cSDH}$.

\section{Methods}

\section{Survey Design}

An electronic online survey consisting of 12 questions was created (Survey Monkey; https://www.surveymonkey. com). Questions covered basic demographic data about the responder (age, gender, career level, country of practice), along with individual disease-specific information (case load, follow-up policy).

The key questions addressed the responder's personal experience, perception, and opinion with regard to skin depressions, patient satisfaction, and surgical treatment options (Table 1). Responders were asked to rate some questions on a 5-tier Likert-like scale ranging from "Yes, always," through "Yes, often," "Yes, sometimes," "Yes, but rarely" to "No, never." Other questions had to be answered either "yes" or "no." In addition to responding to the closed questions, responders had the option to comment freely on the survey or the topic in general, using a dedicated field.

\section{Survey Distribution}

The survey addressed neurosurgeons at all career levels. It was sent to registered members of the European Association of Neurosurgical Societies (EANS; standardized email invitations sent out by the EANS office staff), as well as to neurosurgeons practicing in different parts of the world. For the latter, neurosurgeons in Africa, Asia, Australasia, Europe, North America, and South America were identified by a semistandardized Internet search: lists of neurosurgical departments per country were obtained from websites of the national neurosurgical societies, if available. If the email addresses of the physicians were provided on the department's homepage, group email invitations were sent to all individual email addresses per department. If neurosurgical departments did not list the email addresses of their physicians on the homepage, email invitations were sent to the chief secretary, with a request to forward our email invitation to all neurosurgeons in that particular department.

Repeated survey participation using the same IP address was not possible. No reminder emails were sent in case of nonresponse, to respect the decision of nonparticipation. Questionnaires from all participants who responded between August 28, 2018, and December 7, 2018, and all responses that had complete demographic and survey data were included in the final analysis.

\section{Statistical Considerations}

Continuous variables were reported as means with standard deviation; t-tests were used to compare groups. Frequency distributions and summary statistics were assessed for categorical variables with chi-square tests for group comparison. Some categorical variables were dichotomized in order to calculate the effect sizes of relationships using logistic regression; results were presented as odds ratios with $95 \%$ confidence intervals. A linear regression model was built for analysis of the relationship between a surgeon's attitude toward the placement of burr-hole covers and the nominal gross domestic product (GDP) per capita in US dollars (\$), as reported by the 
TABLE 1. Structure of the questionnaire used

\begin{tabular}{|c|c|}
\hline Question & Answer Options \\
\hline 1. What is your age? & SC: $0-100$ years \\
\hline 2. Gender & SC: male; female \\
\hline 3. Level of practice & $\begin{array}{l}\text { SC: } \\
\text { Resident } \\
\text { Fellow (defined as additional training near the end or after } \\
\text { residency) } \\
\text { Consultant }<5 \text { years after finishing the residency } \\
\text { Consultant }>5 \text { years after finishing the residency } \\
\text { Head of department } \\
\text { Other (please specify) }\end{array}$ \\
\hline 4. In what country do you work? & Afghanistan-Zimbabwe (all countries listed in alphabetical order) \\
\hline $\begin{array}{l}\text { 5. How many burr-hole trepanations for cSDH do you perform } \\
\text { per year on average? }\end{array}$ & $\begin{array}{l}\text { SC: } \\
\quad<5 \\
\quad 5-10 \\
11-15 \\
\quad>15\end{array}$ \\
\hline $\begin{array}{l}\text { 6. Do you personally see cSDH patients for follow-up in } \\
\text { outpatient clinics? }\end{array}$ & $\begin{array}{l}\text { SC: } \\
\text { Yes, always } \\
\text { Yes, often } \\
\text { Yes, sometimes } \\
\text { Yes, but rarely } \\
\text { No, never }\end{array}$ \\
\hline $\begin{array}{l}\text { 7. Based on your personal experience, do you consider "skin } \\
\text { depressions" over the burr-hole trepanation site as a clini- } \\
\text { cally important issue for patients? }\end{array}$ & $\begin{array}{l}\text { SC: } \\
\text { Yes } \\
\text { No }\end{array}$ \\
\hline $\begin{array}{l}\text { 8. Do your patients complain about "skin depressions" and } \\
\text { associated "unsatisfying aesthetic results" in the region of } \\
\text { the burr-hole trepanation? }\end{array}$ & $\begin{array}{l}\text { SC: } \\
\text { Yes, always } \\
\text { Yes, often } \\
\text { Yes, sometimes } \\
\text { Yes, but rarely } \\
\text { No, never }\end{array}$ \\
\hline $\begin{array}{l}\text { 9. Do you personally cover the burr hole(s) with a burr-hole } \\
\text { cover during surgery? }\end{array}$ & $\begin{array}{l}\text { SC: } \\
\text { Yes, always } \\
\text { Yes, often } \\
\text { Yes, sometimes } \\
\text { Yes, but rarely } \\
\text { No, never }\end{array}$ \\
\hline $\begin{array}{l}\text { 10. If you do not use burr-hole covers for this indication, which } \\
\text { are the reasons (multiple answers possible)? }\end{array}$ & $\begin{array}{l}\text { MC: } \\
\text { Fear of increased complication rate, e.g., infection, recurring } \\
\text { cSDH, allergic reaction, material failure } \\
\text { No expected benefit (no proven "added value" of burr-hole } \\
\text { cover placement } \\
\text { Too expensive } \\
\text { Technical difficulty with handling the subdural/subperiosteal } \\
\text { drain } \\
\text { Other (please specify) }\end{array}$ \\
\hline $\begin{array}{l}\text { 11. Would you consider using burr-hole covers in cSDH } \\
\text { patients (more often), if a randomized controlled study had } \\
\text { demonstrated its safety and efficacy in improving patient } \\
\text { satisfaction? }\end{array}$ & $\begin{array}{l}\text { SC: } \\
\text { Yes } \\
\text { No }\end{array}$ \\
\hline $\begin{array}{l}\text { 12. Do you have any other comments, questions, or con- } \\
\text { cerns? }\end{array}$ & Please specify \\
\hline
\end{tabular}

$\mathrm{MC}=$ multiple-choice answer; $\mathrm{SC}=$ single-choice answer.

This table contains the 12 original questions that were part of the online survey on practice variations with regard to burr-hole cover placement for $\mathrm{CSDH}$. 
TABLE 2. Basic demographic characteristics of the $\mathbf{5 7 6}$ survey responders who provided complete data

\begin{tabular}{|c|c|}
\hline Characteristic & Value \\
\hline Age in yrs (mean \pm SD) & $42.4 \pm 10.5$ \\
\hline \multicolumn{2}{|l|}{ Gender } \\
\hline Male & $498(86.5 \%)$ \\
\hline Female & $78(13.5 \%)$ \\
\hline \multicolumn{2}{|l|}{ Level of practice } \\
\hline Resident & $114(19.8 \%)$ \\
\hline Fellow & $40(6.9 \%)$ \\
\hline Junior consultant & $122(21.2 \%)$ \\
\hline Senior consultant & $210(36.5 \%)$ \\
\hline Head of department & $78(13.5 \%)$ \\
\hline Other & $12(2.1 \%)$ \\
\hline \multicolumn{2}{|l|}{ Continent of practice } \\
\hline Africa & $20(3.5 \%)$ \\
\hline Asia & $68(11.8 \%)$ \\
\hline Australasia & $11(1.9 \%)$ \\
\hline Europe & $446(77.4 \%)$ \\
\hline North America & $16(2.8 \%)$ \\
\hline South America & $15(2.6 \%)$ \\
\hline \multicolumn{2}{|c|}{$\begin{array}{l}\text { Average annual case load of burr-hole trepanations } \\
\text { for cSDH }\end{array}$} \\
\hline$<5$ & $54(9.4 \%)$ \\
\hline $5-10$ & $96(16.7 \%)$ \\
\hline $11-15$ & $108(18.7 \%)$ \\
\hline$>15$ & $318(55.2 \%)$ \\
\hline \multicolumn{2}{|c|}{ Personally seeing cSDH patients for follow-up } \\
\hline Yes, always & $175(30.4 \%)$ \\
\hline Yes, often & $198(34.4 \%)$ \\
\hline Yes, sometimes & $103(17.9 \%)$ \\
\hline Yes, but rarely & $68(11.8 \%)$ \\
\hline No, never & $32(5.6 \%)$ \\
\hline
\end{tabular}

Data are presented as number of respondents (\%) unless otherwise indicated.

United Nations (2016 values obtained from https://unstats. un.org/unsd/snaama/selbasicFast.asp).

The software used for the statistical analysis and graphical illustration was Stata v14.2 (StataCorp LP). All p values $<0.05$ were considered statistically significant.

\section{Ethical Considerations}

Survey participation was voluntary. No patient data were collected. Formal consent is not required for this type of study.

\section{Results}

A total of 5074 survey invitations were sent, and 604 responses were received (response rate of 12\%). Of the 604 responses, 28 responses had to be excluded (4.6\%) because relevant data was missing. Data from 576 responses (95.4\%) were used for the final analysis.

Details on the survey sample are summarized in Ta-

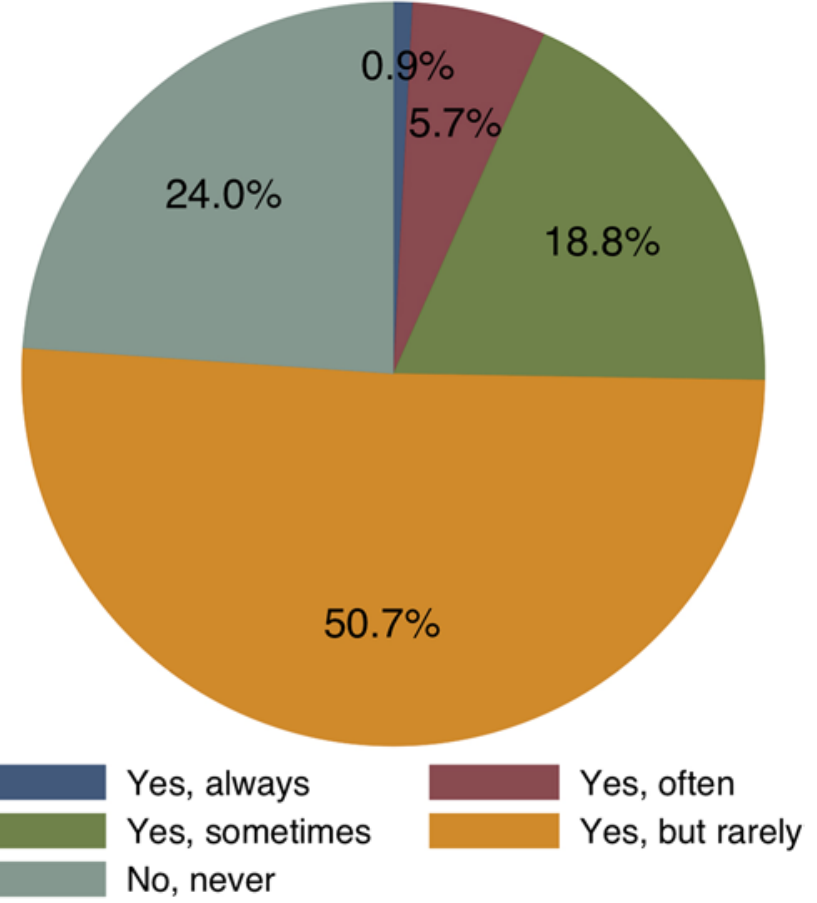

FIG. 2. Pie chart providing an overview on the use of burr-hole covers after burr-hole trepanation for cSDH. Responses to the question: "Do your patients complain about 'skin depressions' and associated 'unsatisfying aesthetic results' in the region of the burr-hole trepanation?" Results are presented as relative frequency of survey response (in \%).

ble 2. Survey responders had a mean age of 42.4 years (SD 10.5), and the majority were male (86.5\%). Most responses were obtained from senior consultant neurosurgeons $(36.5 \%)$, followed by junior consultants $(21.2 \%)$, residents (19.8\%), department heads (13.5\%), and fellows (6.9\%). Most responses were from Europe (77.4\%; Table 2 ), and the highest number of completed questionnaires per country were received from Germany (60), the United Kingdom (50), and the Netherlands (49), with Greece (26), Switzerland (25), Sweden and Italy (each 24), Austria (23), Belgium (22), and Spain (20) following. (For a complete list, see Supplemental Table 1.) Fifty-five percent (55.2\%) of responders indicated performing more than 15 burrhole trepanation procedures per year, and the vast majority (94.4\%) indicated seeing cSDH patients in clinics more or less often for follow-up examinations.

\section{Relevance of Skin Depression}

About a third (31.6\%) of neurosurgeons stated that they consider skin depressions a relevant issue after burrhole trepanation for $\mathrm{cSDH}$. Approximately three-quarters (76.0\%) indicated that their patients complained about skin depressions and/or unfavorable aesthetic outcome after burr-hole trepanation for cSDH more or less frequently at clinical follow-up (Fig. 2), whereas $24.0 \%$ stated that their patients never complain.

Female neurosurgeons were less likely to consider skin depressions after burr-hole trepanation relevant (odds ratio [OR] 0.56, 95\% confidence interval [CI] 0.32-0.99, p $=0.047)$. There was a significant difference with respect 


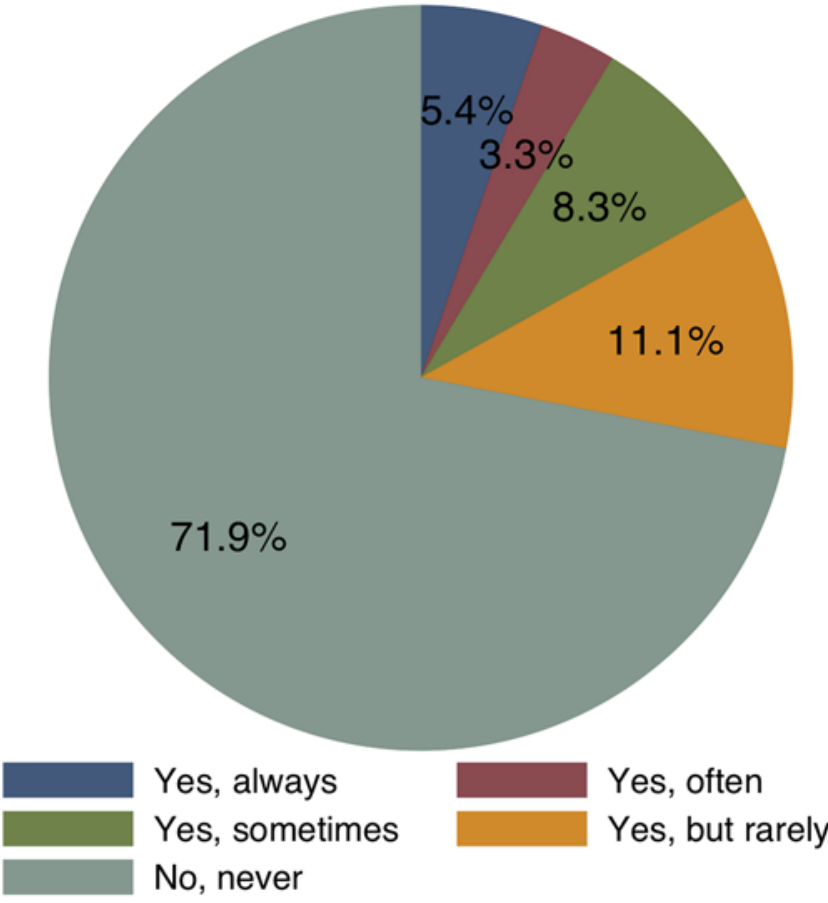

FIG. 3. Pie chart illustrating the responses to the question: "Do you personally cover the burr-hole(s) with a burr-hole cover during surgery?" Results are presented as relative frequency of survey response (in \%).

to the responder's career level ( $\mathrm{p}<0.001$ ), with $55.0 \%$ of fellows confirming its relevance, followed by senior consultants (30.0\%), department heads $(29.5 \%)$, junior consultants $(27.8 \%)$, and residents (27.2\%). Responders from Australasia (54.6\%) and Asia (54.4\%) considered skin depressions most relevant, followed by those from Africa (45.0\%), South America (40.0\%), North America $(31.3 \%)$, and Europe (26.7\%; p < 0.001). The responder's age was not associated with the response to this question $(\mathrm{p}=0.821)$.

\section{Patterns of Practice: Application of Burr-Hole Covers}

About three-quarters of responding neurosurgeons (71.9\%) stated that they have never applied burr-hole covers for this indication (Fig. 3); the remaining respondents indicated that they apply them always (5.4\%), often (3.3\%), sometimes $(8.3 \%)$, or rarely $(11.1 \%)$.

Again, females tended to apply burr-hole covers less than males (OR 0.62, 95\% CI 0.35-1.11, p = 0.110): $29.3 \%$ of male and $20.5 \%$ of female responders stated that they had applied burr-hole covers for cSDH $(p=0.108)$. There were no differences in the application of burr-hole covers and the responder's career level $(\mathrm{p}=0.881)$ or age $(\mathrm{p}=$ 0.795).

The frequency of burr-hole cover placement varied significantly among world regions $(\mathrm{p}<0.001)$ with most responders in South America (60.0\%) and North America (56.3\%) placing burr-hole covers, followed by Australasia (45.5\%), Asia (39.7\%), Africa (35.0\%), and Europe (23.5\%).

Figure 4 illustrates the relationship of a country's GDP per capita and the likelihood of neurosurgeons from that country to apply burr-hole covers for the studied indication. The fitted (red) line shows no higher tendency of surgeons working in countries with higher GDP per capita to apply burr-hole covers (coefficient $435.9,95 \%$ CI -1086.7 to $1958.5, \mathrm{p}=0.574)$.

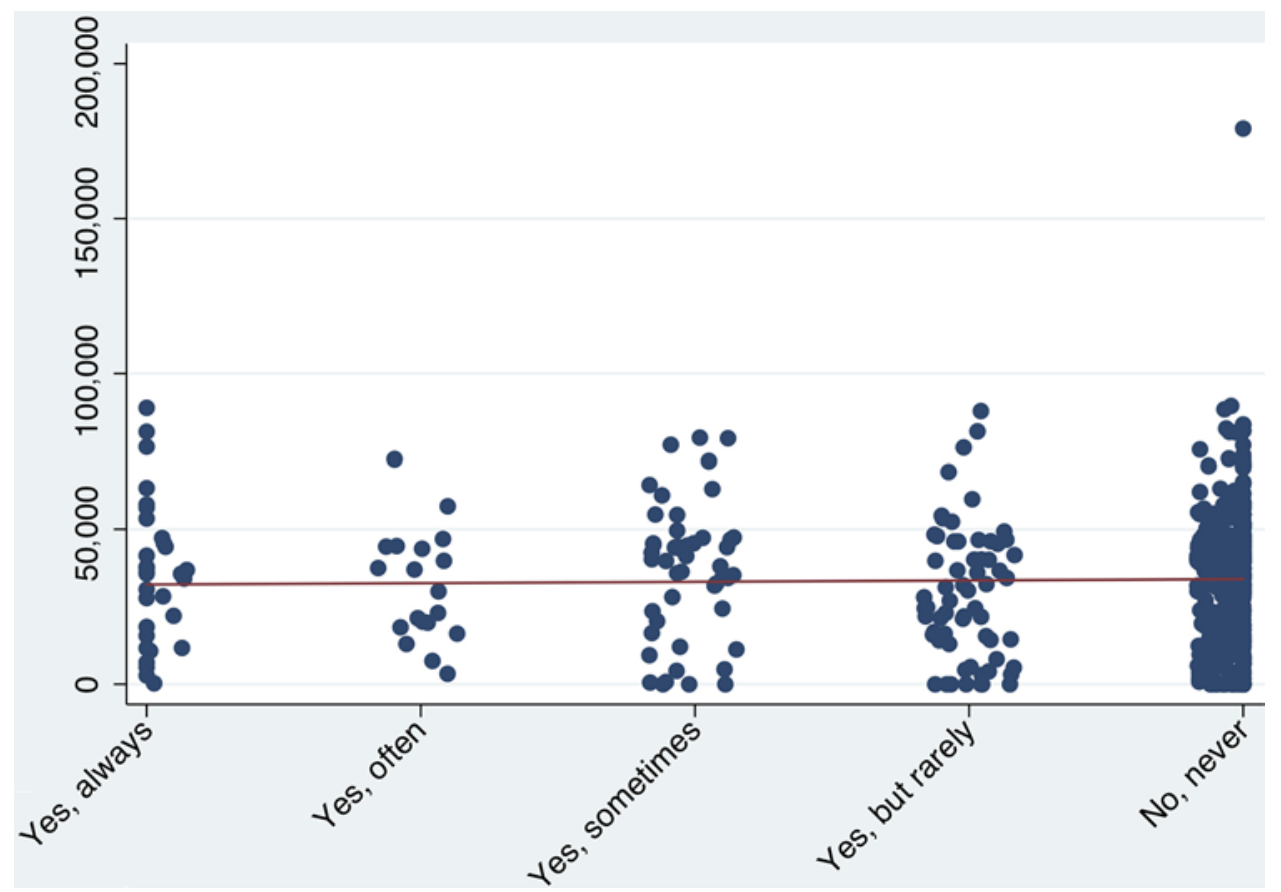

FIG. 4. Scatterplot illustrating the relationship between a country's GDP per capita in US dollars (y-axis) and a surgeon's attitude toward the placement of burr-hole covers after trepanation for cSDH (x-axis). The fitted (red) line shows no higher tendency of surgeons working in countries with higher GDP per capita to apply burr-hole covers (coefficient 435.9, 95\% Cl -1086.7 to 1958.5, $p=0.574$ ). 


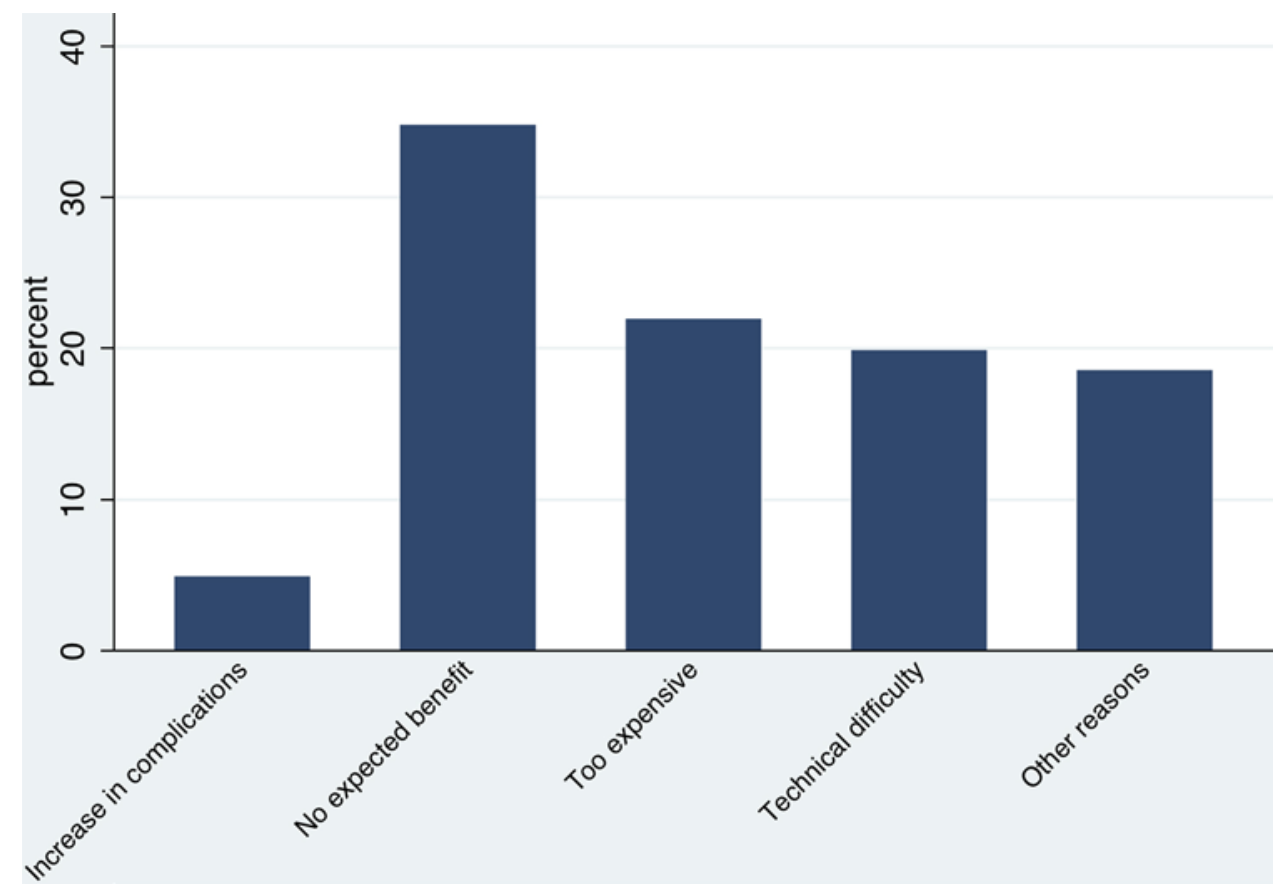

FIG. 5. Bar graph illustrating the responses to the question: "If you do not use burr-hole covers for this indication, which are the reasons (multiple answers possible)?" The x-axis indicates the response options; the y-axis, the relative frequency of survey response (in \%).

\section{Reasons for Nonplacement of Burr-Hole Covers}

The most frequent reasons for not placing burr-hole covers in this context were "no expected benefit" (34.8\%), "too expensive" (21.9\%), technical difficulty (19.9\%), and fear of "increase in complications" (4.9\%; Fig. 5). Furthermore, $18.5 \%$ of survey participants indicated "other reasons," which are listed in Table 3.

\section{Willingness to Change Patterns of Practice}

The majority of responders $(77.5 \%)$ stated that they would consider the placement of burr-hole covers in the future, if an adequately designed randomized controlled trial (RCT) demonstrated its safety and efficacy in improving patient satisfaction.

Responders who answered this question in the affirmative worked in countries with lower GDP per capita (mean $\$ 31,524.4 \pm \$ 20,319.7)$ compared to responders that answered in the negative (mean $\$ 40,990.4 \pm \$ 21,068.5$, $p<$ 0.001 ). Also, affirmative responses came from younger responders (mean $41.7 \pm 10.4$ years vs $44.6 \pm 10.5$ years, $p=$ 0.005 ), and female responders were less likely to consider burr-hole cover placement in the future (OR $0.56,95 \%$ CI $0.33-0.95, \mathrm{p}=0.030$ ).

Several respondents who gave a negative response to this question specified that they would consider the demonstration of cost-effectiveness important before they would consider applying burr-hole covers on a regular basis.

\section{Discussion}

This survey set out to explore differences in opinions about and attitudes regarding the placement of burr-hole covers after trepanation for the evacuation of cSDH. De- spite their small size, these skull defects may result in undesirable skin depressions (Fig. 1). Nevertheless, probably because they appear in a delayed fashion, these skin depressions have been poorly studied. ${ }^{4,12}$ In theory, burrhole covers represent an effective, easy-to-apply, and relatively inexpensive solution to prevent cosmetically and functionally unfavorable skin depressions. ${ }^{4,12}$ The survey demonstrates that-despite the fact that the majority of neurosurgeons have encountered patients who reported skin depressions (76.0\%; Fig. 2) - general awareness of the importance of skin depressions after burr-hole trepanation remains low (31.6\%), and only a quarter of neurosurgeons place burr-hole covers more or less frequently (28.1\%; Fig. 3). Moreover, the survey showed that that lack of evidence for the efficacy and safety was the most important reason for nonplacement of burr-hole covers (Fig. 5). Three-quarters of neurosurgeons indicated that they would consider a change in practice if an RCT were to demonstrate its efficacy and safety.

\section{Awareness and Perception of Relevance}

Our motivation to study this undesired effect of burrhole trepanation derived from personal clinical experience, where-over the course of the last years-we occasionally encountered patients who presented stigmatizing skin depressions (Fig. 1). ${ }^{7}$ Especially in bald patients or those with sparse scalp hair, burr-hole cover placement seemed to us to be a reasonable tool for preventing unfavorable aesthetic outcomes. ${ }^{12}$ Given the fact that the male-to-female ratio among cSDH patients is approximately 3:1 and cSDH is a common disorder of the elderly, sparse scalp hair affects a great proportion of all cSDH patients. It is interesting to note in this regard that the awareness for the relevance 
TABLE 3. Reasons for nonplacement of burr-hole covers, as specified by comments

\begin{tabular}{l}
\hline Selective application for certain age \& gender constellations \\
Concern for being criticized by senior staff when applying burr-hole \\
covers \\
Use of drilled bone or TALOS burr-hole cover (N.G. Med) to fill out the \\
trepanation defect \\
Selective use for frontal burr holes only \\
\hline Use of burr-hole covers only in case no drainage is used \\
\hline Application only if refundable \\
Use of alternative products (e.g., Spongostan [Ethicon Johnson \& \\
Johnson] or bone wax) to fill out the trepanation defect \\
\hline Problems with burr-hole covers because of standard placement of \\
subdural drains \\
\hline Considered unnecessary procedural expense as only few encounters \\
w/ patients who complained \\
\hline Burr-hole area hidden by hair-unnecessary to cover up additionally \\
\hline Cost-effectiveness not proven \\
\hline Judicious use of alternative techniques-such as twist drill-to avoid \\
burr holes \\
\hline Meticulous soft-tissue closure (placement of burr hole under muscle \\
layer, whenever possible) \\
\hline Risk of insufficient drainage through burr-hole cover into standard \\
subgaleal drain placement/subcutaneous pouch \\
\hline Prolonged operation time \\
\hline Risk of re-accumulation of SDH \\
\hline Placement of burr-hole cover, if required, in a 2nd operation \\
\hline Risk of commercial bias \\
\hline No practice guide available in the country \\
Semilunar incision (i.e., not over the burr hole) to prevent wound \\
breakdown \\
\hline
\end{tabular}

of skin depressions was about twice as high among male neurosurgeons as it was among female neurosurgeons ( $\mathrm{p}=$ 0.047 ). Also, about $30 \%$ of male but only $20 \%$ of female neurosurgeons indicated that they placed burr-hole covers from time to time $(\mathrm{p}=0.108)$ and female neurosurgeons were about half as willing to consider future burr-hole cover placement (OR 0.56, 95\% CI 0.33-0.95, $\mathrm{p}=0.030)$.

The survey moreover revealed substantial differences in the perception of relevance based on the responder's career level and region of practice. More generally, a substantial variation in the perception of relevance of undesirable skin depression among neurosurgeons might be explained by the often short-term hospitalization and relatively fast recovery as well the lack of imminent health risks of skin depressions in this patient group. In our experience, scalp depressions aggravate slowly over time with the resolution of wound swelling in the early stage and atrophy of soft tissue in later stages. However, as cSDH patients with favorable clinical courses are usually only followed in the short-term in the outpatient clinic, these changes are likely to remain unnoticed by the treating neurosurgeon in a considerable proportion of cases. In this survey, most neurosurgeons $(82.6 \%$; always in $30.4 \%$, often in $34.4 \%$, and sometimes in $17.9 \%$ ) indicated seeing cSDH patients personally at follow-up, but in order to keep the survey reasonably short we did not evaluate the typical length of follow-up.

It is important to consider that advances in medicine and consequently prolonged life expectancy have led to an increase in the population of elderly cSDH patients with long-term active participation in life after burr-hole trepanation. In our patient population, we have become aware that a patient's perception of the esthetic/cosmetic result is an important determinant of satisfaction with the treatment result. Nowadays, patients do not only expect the performance of a basic surgical procedure, but the delivery of favorable treatment outcomes together with excellent service. ${ }^{11}$ We hypothesize that the awareness of skin depressions will necessarily increase among the neurosurgical community within the next years. Altogether it must be acknowledged, however, that placement of burr-hole covers is far from being a "gold standard" in today's clinical practice, considering the low rates of use and scarce literature regarding this issue. ${ }^{1,4}$

\section{Reasons for Nonplacement of Burr-Hole Covers}

We were interested in determining the reasons why neurosurgeons choose not to apply burr-hole covers and hypothesized that important reasons might be lack of awareness/data, associated costs, and technical difficulties-depending on the type of drain-as well as fear of increased perioperative complications. The survey responses clearly show that the lack of high-quality data regarding this issue was the main reason for nonplacement, making the application of burr-hole covers a matter of the individual surgeon's judgment.

The second most important reason was additional costs. In our practice, the additional costs for placement of 2 burrhole plates and 4 screws in a patient with unilateral cSDH amount to about 260 Swiss francs (about 225 EUR/\$260 [USD]). As discussed earlier, ${ }^{12}$ there are currently no data available to estimate the perceived value of burr-hole cover placement. We plan to address this point within the framework of a clinical trial.

Technical difficulties when placing the burr-hole cover together with a subdural or subperiosteal drain were indicated as the third major reasons for nonplacement. At our institution, we prefer placement of subperiosteal drains in the vast majority of cases, as we consider the safety profile more favorable compared to subdural drain placement. ${ }^{2}$ For the application of burr-hole covers we have developed a standard operating procedure (SOP). We personally have not encountered difficulties passing the burr-hole cover underneath the previously placed subperiosteal drainage. We routinely fill the subdural compartment with physiological $0.9 \%$ saline irrigation, and this can safely be performed through the semipermeable burr-hole cover membranes. A considerable number of responders used the free-text option of the survey to point out that they were not aware of burr-hole cover solutions that allow for the placement of subdural drains. Im et al. placed subdural drains, using burr-hole plates with a small gap to account for the drain (Synthes GmbH). ${ }^{4}$ We have no personal experience with those burr-hole plates, but theoretically, subdural drain placement does not impede burr-hole cover application. 
Less than $5 \%$ of responders were concerned about a possible peri- or postoperative increase in complications associated with burr-hole cover placement. Of note, in our recently published retrospective analysis we did not identify a patient with a surgical-site infection (SSI) after placement of a titanium burr-hole cover. ${ }^{12}$ Furthermore, there was no intraoperative complication associated with burr-hole cover placement. ${ }^{12}$ In accordance, the current literature suggests no obvious increase in infectious complications. Im et al. ${ }^{4}$ report 2 cases of SSI in their series of 196 patients, which included 96 patients who had burr-hole covers; both cases of SSI occurred in patients who had not received a burr-hole cover.

\section{Strengths and Limitations}

This survey assessed practice patterns regarding burrhole cover placement after trepanation for $\mathrm{CSDH}$ in a large and international cohort of neurosurgeons across all career levels. Responses were received from a large number of countries, representing 6 continents and including countries with a wide span of economical wealth (GDP per capita ranging from $\$ 722$ to $\$ 168,004)$.

While a research question such as this one is likely to be answered best with a survey, there are a number of limitations inherent to this type of study. Voluntary, nonincentivized survey participation can result in a survey participation or nonresponse bias: the average responder (or nonresponder) possesses certain traits that increase (or decrease) the likelihood of their participating in the survey. Specifically, it is conceivable that neurosurgeons who have encountered patients reporting skin depressions and an aesthetically displeasing scar after burr-hole trepanation are more likely to participate in such a survey, as they personally perceive this as an important issue. The generally low response rate makes the study more likely to be subject to such a bias.

Despite these limitations, the study allows for important conclusions regarding current practice variations and the willingness to adapt clinical practice if future highquality data demonstrate higher patient satisfaction without an increase in associated complications.

\section{Future Outlook}

A prospective, single-blinded RCT has recently started at the University Hospital Zurich. It is investigating whether the addition of a burr-hole cover results in superior aesthetic outcomes, without an increase in complication risks (COveRs to impRove EsthetiC ouTcome after Surgery for Chronic subdural hemAtoma by buRr hole trepanation; CORRECT-SCAR trial). We hope that this study will help provide answers to the many currently open questions regarding burr-hole cover placement after trepanation for cSDH.

\section{Conclusions}

The awareness of aesthetically displeasing skin depressions after burr-hole trepanation is rather low. Today, burrhole covers are infrequently applied in an intention to reduce the rate of skin depressions and improve the aesthetic outcome after trepanation for the evacuation of cSDH.
There are significant differences in the patterns of practice among individual surgeons, and significant associations were found between the use of burr-hole covers and both surgeon gender and world region. Additional scientific evidence is needed to shed light upon the question of whether burr-hole cover placement for this indication is beneficial.

\section{Acknowledgments}

We thank all neurosurgeons who took the time to respond to the survey, contributing to the understanding of current practice. We want to highlight the kind support of the European Association of Neurosurgical Societies (EANS), who provided their survey tool; in particular, we are grateful for the assistance of Francesco Sala, Amy Pinchbeck-Smith, and Petra Koubova, who made it possible to distribute the survey among EANS members. We also acknowledge Angelos Kolias' great efforts to distribute the survey among WFNS (World Federation of Neurosurgical Societies) members and neurosurgeons in the United Kingdom.

\section{Appendix}

Further contributors of the CORRECT-SCAR study group are listed in alphabetical order.

David Bellut, MD, Oliver Bichsel, MD, Laurenz PeltenburgBrechneff, MD, Giuseppe Esposito, MD, Jorn Fierstra, MD, PhD, Basil E. Grüter, MD, Anna-Sophie Hofer, MD, Dilek Könü-Leblebicioglu, MD, Niklaus Krayenbühl, MD, Alexander Küffer, MD, Marian C. Neidert, MD, Markus F. Oertel, MD, Philip-Rudolf Rauch, MD, Pierre Scheffler, MD, Martina Sebök, MD, Carlo Serra, MD, Lennart H. Stieglitz, MD, Nicolas R. Smoll, MBBS, Lazar Tosic, MD, Bas van Niftrik, MD, and Stefanos Voglis, MD.

\section{References}

1. Baschera D, Tosic L, Westermann L, Oberle J, Alfieri A: Treatment standards for chronic subdural hematoma: results from a survey in Austrian, German, and Swiss neurosurgical units. World Neurosurg 116:e983-e995, 2018

2. Bellut D, Woernle CM, Burkhardt JK, Kockro RA, Bertalanffy H, Krayenbühl N: Subdural drainage versus subperiosteal drainage in burr-hole trepanation for symptomatic chronic subdural hematomas. World Neurosurg 77:111-118, 2012

3. Gelabert-González M, Iglesias-Pais M, García-Allut A, Martínez-Rumbo R: Chronic subdural haematoma: surgical treatment and outcome in 1000 cases. Clin Neurol Neurosurg 107:223-229, 2005

4. Im TS, Lee YS, Suh SJ, Lee JH, Ryu KY, Kang DG: The efficacy of titanium burr hole cover for reconstruction of skull defect after burr hole trephination of chronic subdural hematoma. Korean J Neurotrauma 10:76-81, 2014

5. Kolias AG, Chari A, Santarius T, Hutchinson PJ: Chronic subdural haematoma: modern management and emerging therapies. Nat Rev Neurol 10:570-578, 2014

6. Kudo H, Kuwamura K, Izawa I, Sawa H, Tamaki N: Chronic subdural hematoma in elderly people: present status on Awaji Island and epidemiological prospect. Neurol Med Chir (Tokyo) 32:207-209, 1992

7. Maldaner N, Sosnova M, Sarnthein J, Bozinov O, Regli L, Stienen MN: Burr hole trepanation for chronic subdural hematomas: is surgical education safe? Acta Neurochir (Wien) 160:901-911, 2018

8. Sahyouni R, Goshtasbi K, Mahmoodi A, Tran DK, Chen JW: chronic subdural hematoma: a historical and clinical perspective. World Neurosurg 108:948-953, 2017

9. Santarius T, Kirkpatrick PJ, Ganesan D, Chia HL, Jalloh I, Smielewski P, et al: Use of drains versus no drains after 
burr-hole evacuation of chronic subdural haematoma: a randomised controlled trial. Lancet 374:1067-1073, 2009

10. Santarius T, Lawton R, Kirkpatrick PJ, Hutchinson PJ: The management of primary chronic subdural haematoma: a questionnaire survey of practice in the United Kingdom and the Republic of Ireland. Br J Neurosurg 22:529-534, 2008

11. Stienen MN, Serra C, Stieglitz LH, Krayenbühl N, Bozinov O, Regli L: UniversitätsSpital Zürich: 80 years of neurosurgical patient care in Switzerland. Acta Neurochir (Wien) 160:3-22, 2018

12. Vasella F, Akeret K, Smoll NR, Germans MR, Jehli E, Bozinov $\mathrm{O}$, et al: Improving the aesthetic outcome with burr hole cover placement in chronic subdural hematoma evacuation-a retrospective pilot study. Acta Neurochir (Wien) 160:2129-2135, 2018

13. Yan K, Gao H, Zhou X, Wu W, Xu W, Xu Y, et al: A retrospective analysis of postoperative recurrence of septated chronic subdural haematoma: endoscopic surgery versus burr hole craniotomy. Neurol Res 39:803-812, 2017

14. Zumofen D, Regli L, Levivier M, Krayenbühl N: Chronic subdural hematomas treated by burr hole trepanation and a subperiostal drainage system. Neurosurgery 64:1116-1122, 2009

\section{Disclosures}

The authors report no conflict of interest concerning the materials or methods used in this study or the findings specified in this paper. No financial support was received for this study. The Stryker company (Stryker European Operations B.V. at Heri- kerbergweg 110, $1101 \mathrm{CM}$ Amsterdam, The Netherlands) has agreed to financially support an investigator-initiated clinical trial addressing the research question, whether the placement of burr-hole covers for chronic subdural hematoma is beneficial. However, this survey was conducted outside the study agreement, without knowledge, incentive or influence of Stryker.

\section{Author Contributions}

Conception and design: all authors. Acquisition of data: Stienen, Velz, Vasella, Akeret, Fernandes Dias, Jehli, Germans. Analysis and interpretation of data: Stienen, Velz, Vasella, Akeret, Jehli, Germans. Drafting the article: Stienen, Velz, Vasella. Critically revising the article: Akeret, Fernandes Dias, Jehli, Bozinov, Regli, Germans. Reviewed submitted version of manuscript: Stienen. Approved the final version of the manuscript on behalf of all authors: Stienen. Statistical analysis: Stienen. Administrative/technical/material support: Stienen, Jehli, Bozinov, Regli, Germans. Study supervision: Stienen, Jehli, Bozinov, Regli, Germans.

\section{Supplemental Information Online-Only Content}

Supplemental material is available online.

Supplemental Table 1. https://thejns.org/doi/suppl/10.3171/ 2019.8.FOCUS19245.

\section{Correspondence}

Martin N. Stienen: University Hospital Zurich, Clinical Neuroscience Center, University of Zurich, Switzerland. mnstienen@gmail. com. 